\title{
Research on the Innovative Mode of Integration of Information Technology and Education
}

\author{
Liu Guohua \\ School of Mechanical Engineering, Tiangong University \\ Tianjin 300387, China
}

\begin{abstract}
This paper introduces the basic functions and characteristics of the Rain Classroom platform based on information technology. By using the integration of information technology and Control Engineering course teaching, a mixed teaching mode of control engineering course based on Rain Classroom is designed and applied to specific teaching practice. The results show that, the engineering thinking, learning habits, self-learning ability, learning interest and learning enthusiasm of the experimental class have been greatly improved compared with before after the practice of blended teaching.
\end{abstract}

\section{INTRODUCTION}

Since the 1990s, information technology has been continuously applied in the field of education, but it is only a simple combination of means and methods, which does not have a fundamental impact on the development of education. The reason is that the education reform needs major structural change supported by technology, rather than gradual repair. Therefore, the deep integration of information technology and subject teaching has become the development trend of education reform after the "Deep Integration of Information Technology and Education" was first put forward in "the Outline of National Medium and Long Term Education Reform and Development Plan (2010-2020) "released in 2010 ${ }^{[1]}$.

However, the deep integration of information technology and subject teaching is still in the early stage, which needs continuous research and practice to enrich the theory of integration.

Based on this understanding, this paper designs and implements teaching cases on the basis of Control Engineering teaching practice and theoretical learning, and increases the integration depth of information technology and subject teaching. Through the problembased Rain Classroom hybrid teaching design and practice research, this paper discusses the application of Rain Classroom in the university education based on the problem-based teaching, which is not only the landing of the teaching and research results to support the university classroom reform, but also an important step to promote the independent learning of college students. It can solve the learning problems, life and work problems.

\section{CONSTITUTION AND ANALYSIS OF A BLENDED TEACHING MODEL INTEGRATED WITH RAIN CLASSROOM}

In order to solve the problem that information technology and control engineering curriculum teaching are difficult to integrate, and make it possible that information technology can change the teaching structure of traditional Control Engineering classroom, we carry out problemoriented teaching and learning mode through the Rain Classroom tools. It can change the traditional teaching structure of "teacher centered" that teachers dominate the classroom into one that can give full play to teachers' leading role, and it can also highlight the main position of students[2].

With the help of the intelligent teaching tool Rain Classroom, a hybrid teaching mode of online and offline combination of Control Engineering course is designed. The teaching mode combines personalized learning with group cooperative learning, that is, it respects learners' interest in learning and groups learners according to their different cognitive abilities.It not only enables students to improve their ability of autonomous learning, but also enables them to play their own advantages in cooperation and promote the emotional exchange between them. The mixed teaching mode based on Rain Classroom is divided into four parts: before class learning, class learning, after class practice and teaching evaluation ${ }^{[3,4]}$.

\section{1 preparation of teaching}

In the stage of teaching preparation, firstly, it is necessary to analyze the basic situation of students and the basic characteristics of curriculum teaching to determine 
whether it is suitable for hybrid teaching. Secondly, we need to make and select curriculum resources, and determine the online and offline teaching organization mode, teaching content in each stage and design assessment methods ${ }^{[5]}$. Teaching preparation is mainly consisted of the following aspects:

1) In the aspect of teaching design, the teaching objectives of each stage should be clear, the students' differences should be considered, and the individualization of teaching requirements should be reflected.

2) Teaching resources should be rich, including graphic resources, audio and video resources and multiple types of test questions. Moreover, online teaching resources should be able to attract students' interest in learning, inspire them, and prepare for class discussion. At the same time, the teaching resources produced or selected should meet the technical requirements of the network platform ${ }^{[6]}$.

3) The content of teaching should have enough breadth and depth, and the advanced and timeliness of content should also be guaranteed.

4) In terms of teaching process, online and offline should be set up with Q \& A and interaction links, so that students can timely feedback learning problems.Face-toface teaching in offline classroom and after-class practice should focus on discussion, practice, application and exploration, pay attention to the individual development of students, and pay attention to face-to-face cooperation and communication.

5) In the design of evaluation system, we should follow the principles of differentiation of evaluation standards, diversification of evaluation methods, diversification of evaluation subjects, dynamic evaluation process and comprehensive evaluation content, develop a reasonable diversified evaluation system for learners, and evaluate students qualitatively and quantitatively.

\subsection{Pre-class learning}

The teachers issue the teaching task list to the students through the network platform. The students watch the video resources pushed by the teachers, learn relevant theoretical knowledge, complete the self-test questions, and actively participate in the online interactive communication. They feed back the problems encountered in the learning to the teachers, and preliminarily complete the docking of the offline classroom knowledge internalization and after-school knowledge application. Teachers should do a good job of online Q \& A of pre class learning at the same time to prepare for classroom teaching organization. During the implementation of preschool learning, students acquire knowledge points and experience of self-study, and construct their knowledge system and learning experience.

\subsection{Classroom learning}

In the course of classroom learning, the teacher first constructs a complete learning scene, presents learning tasks or discussing topics. Students can independently determine related topics and complete learning tasks through group cooperation. During this process, the teachers carefully observe the situation of each group cooperation discussion, listen to and record the learning difficulties encountered in the group problem discussion, focus on the common problems, adopt a centralized way of explaining the problems of individual groups, and adopt an individual way of guidance. Moreover, each group presents the results of the discussion, and carries out face-to-face communication within and between groups. It can also submit questions on the network platform for online communication. The teacher then evaluates the results submitted by each group.

\subsection{After-class practice}

In the course of after-class practice, the first step is to publish the Control Engineering after-class practice task list and after-class learning resources to students through the network platform. Secondly, according to the learning resources issued by the teacher, the students work in groups to complete the principle analysis, software simulation and experiment of the control system. At the same time, it is necessary for students to complete the test papers pushed online by the teacher.

The implementation of after-class practice stage is mainly to let students master the control system analysis method and verification method of Control Engineering course, to cultivate students' knowledge application ability and practical ability, so as to strengthen the training of vocational skills. The push of after-class test papers is mainly to test the effect of students' staged learning of the Control Engineering course. According to the test results, this paper quantitatively analyzes whether students' learning efficiency has been improved.

\subsection{Teaching evaluation}

Teaching evaluation is an indispensable part in teaching. It measures the whole teaching process and results through effective technical means and gives value judgment on the basis of teaching objectives and corresponding standards. Teaching evaluation can understand the students' mastery of the course, test the teaching effect, diagnose teaching problems, provide feedback information, control the teaching process, guide the teaching direction, and reflect the progress of teaching as a whole. Traditional teaching evaluation focuses on the summary evaluation, usually focusing on the quantitative evaluation of the final examination results. This single evaluation ignores the effect and progress of students in the learning process. The mixed mode of teaching pays attention to the combination of various teaching evaluations and makes a comprehensive evaluation of teaching qualitatively and quantitatively.

The teaching evaluation system of the teaching mode is shown in Fig.1. 


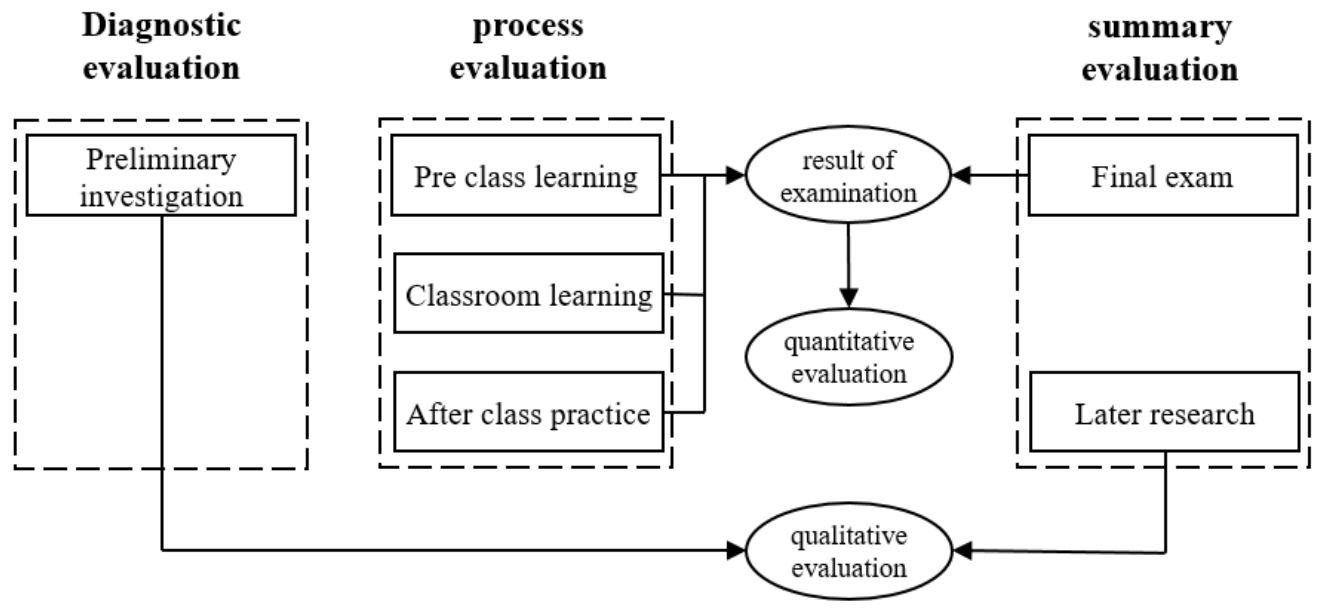

Figure1 The teaching evaluation system.

\section{TEACHING PRACTICE AND TEACHING QUALITY ANALYSIS OF THE BLENDED TEACHING MODE BASED ON RAIN CLASSROOM}

\subsection{Teaching Practice}

The mixed teaching model based on rain classesroom is theoretically feasible, but in order to ensure its operability and effectiveness in practice teaching, it needs to be applied in practice teaching. Therefore, the teaching practice of the mixed teaching mode of Control Engineering course is carried out to explore the feasibility and validity of this mixed teaching mode in the specific practical application, and to modify and improve the teaching mode through the teaching practice link.

Introducing Rain Classroom into teaching mainly is to support students' problem-oriented learning through its function modules such as mobile phone push, learning report feedback, learning trace retention, scanner check-in, anonymous voting statistics, synchronized courseware, bullet screen interaction, submission message, data publishing, etc. And it can make up for one-to-many cognitive guidance limitation, inadequate feedback, lack of interaction, in offline classroom, to implement effective mixed teaching. With the deepening of learning, students can be guided to acquire the ability of analysis and design of control system through self-study and practice, and pay attention to the cultivation of students' systematic and dynamic thinking ability.

\subsection{Teaching Quality Analysis}

This mixed teaching model uses Excel and SPSS24.0 data processing tools to analyze the effect of teaching practice from three aspects: teaching process, goal achievement and teaching reflection, based on online data such as Rain Classroom preview feedback, teaching report, student evaluation, and offline data such as classroom observation, test results, questionnaire survey, interview and so on.

1) Classroom Observation of Teaching Process
Classroom observation refers to both the teachers' classroom teaching behavior and the research methods of teachers or researchers on the classroom.

In this study, the auxiliary tools of classroom observation are mainly the Classroom Student Learning Observation Scale, which records the learning situation of students observed in the classroom. This scale is formulated according to the LICC paradigm, which contains four dimensions: student learning, teacher teaching, course nature and classroom culture. According to the research needs, the scale is formulated from four perspectives with student learning as the core and four observation points.

2) Analysis on the Achievement of Teaching Objectives

In addition to the learning reflected in the analysis of teaching process data, the improvement of teaching objectives including performance, ability and learning experience will be reflected in the analysis of teaching goal achievement degree data, especially the final exam results, which centrally reflects the achievement of teaching goals.

Final-term test results refer only to the score of the test paper (percentage system), excluding the usual results. The distribution of the score segments is shown in Fig.2.

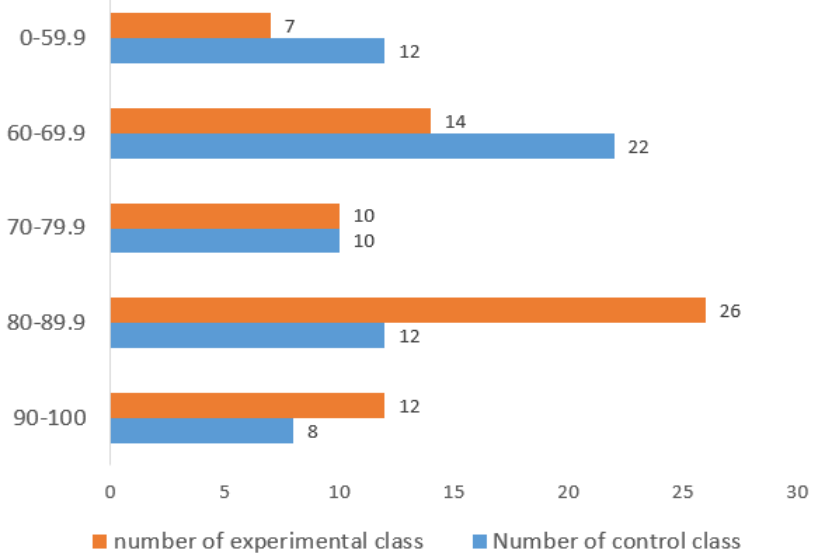

Figure2 The distribution of the final-term test results.

3) Summary of Teaching Reflection 
Through discussions in Discussion Area and questionnaires, more than $67.7 \%$ of students believed that the instant feedback function of the Rain Classroom helped them learn more, but only $37.1 \%$ expressed their preference for using mobile phones to browse the learning content. The results show that most students are accustomed to using mobile phone, but they are not accustomed to mobile phone learning or have not developed mobile learning habits, and have not yet experienced the benefits of mobile phone learning. In this case, more than half of the students still believe that the Rain Classroom immediately feedback function is beneficial to learning.

\section{ConClusion}

By combining theory with practice, this paper makes the following exploration:

1) Research perspective innovation: from the perspective of improving the current situation of classroom teaching in colleges and universities, and promoting the development of college students, by changing the credit-oriented learning style, guiding the teaching design with problem-oriented learning, promoting the classical teaching method into a new era of wisdom teaching, and an effective and feasible teaching model is constructed.

2) Research content innovation: learning from the existing teaching links, strategies and models, in view of the contradiction between the existing problems in college classes and the development prospects of college students, we bring into the advantages of the Rain Classroom in supporting teaching, and an innovative teaching model that integrates the Rain Classroom from five parts is constructed.

3) We haved made full use of the advantages of online teaching: teaching and learning reform and innovation with the deep integration of information technology and education have promoted the change of learning style, improved teaching efficiency, and enriched the problemoriented practical research field of the Rain Classroom teaching.

\section{ACKNOWLEDGMENT}

The completion of this paper is supported by Tiangong University and the author is grateful to the colleagues of Teaching and Research Group of Mechanical Control Engineering for proofreading this manuscript.

\section{REFERENCES}

1. Cong Liang. The Construction Study of College Informationization Teaching Mode under the Backgrou-nd of Big Data[J]. China Educational Technology, 2017,vol.12, pp. 98-102,137.

2. WANG Shuai guo. Rain Classroom:The Wisdom Teaching Tool in the Context of Mobile Internet and Big Data[J]. Modern Educational Technology, 2017,vol.27, pp. 26-32.
3. Wang Zhihua,Zhu Zhiyu. The Use of Study Method of the Problem Direction in the Information Quality Teaching[J].LIBRARY,2007, vol.4, pp.110-111,116.

4. OU YANG Ming,ZHANG Ying.The Study of Instructional Design: the Methodology Perspective on Problem-Oriented[J]. Modern Educational Technology, 2013,vol.23, pp. 35-40.

5. Prince K JAH , Eijs PW L J V , Boshuizen H PA, et al. General competencies of problembased learning (PBL) and non-PBL graduates.[J]. Medical Education, 2010,vol.39, pp.394-401.

6. Xiao K, Wang Q, Chen Y.Application and Introspection of Rain Classroom in Course Teaching $[\mathrm{J}]$. Guangdong Chemical Industry, 2017,vol.44, pp.283-284,298. 